\title{
ICDP Workshop on the Emerging Modern Aerobic Earth System
}

An ICDP workshop on "Archaean-Palaeoproterozoic Transition: Emerging Modern Aerobic Earth System,” was held in Trondheim, Norway on 25-29 September 2005. The Geological Survey of Norway (NGU) organized and supported the workshop with funding from the ICDP.

The concept of studying a critical interval in Earth's history when the biosphere and geosphere experienced global scale changes was discussed during the 2004 Nordic Academy for Advanced Studies field course held in northwestern Russia. An international group of scientists deliberated in the field and decided to propose a scientific drilling project to analyze the best preserved rock record of the hallmark events that typify the Archaean-Palaeoproterozoic (2500-1900 Ma) transition. Subsequent field studies identified potential drilling sites and specific target intervals and objectives, and focused discussions during the ICDP workshop on issues associated with preparing a full drilling proposal on the Russian side of the Fennoscandian Shield.

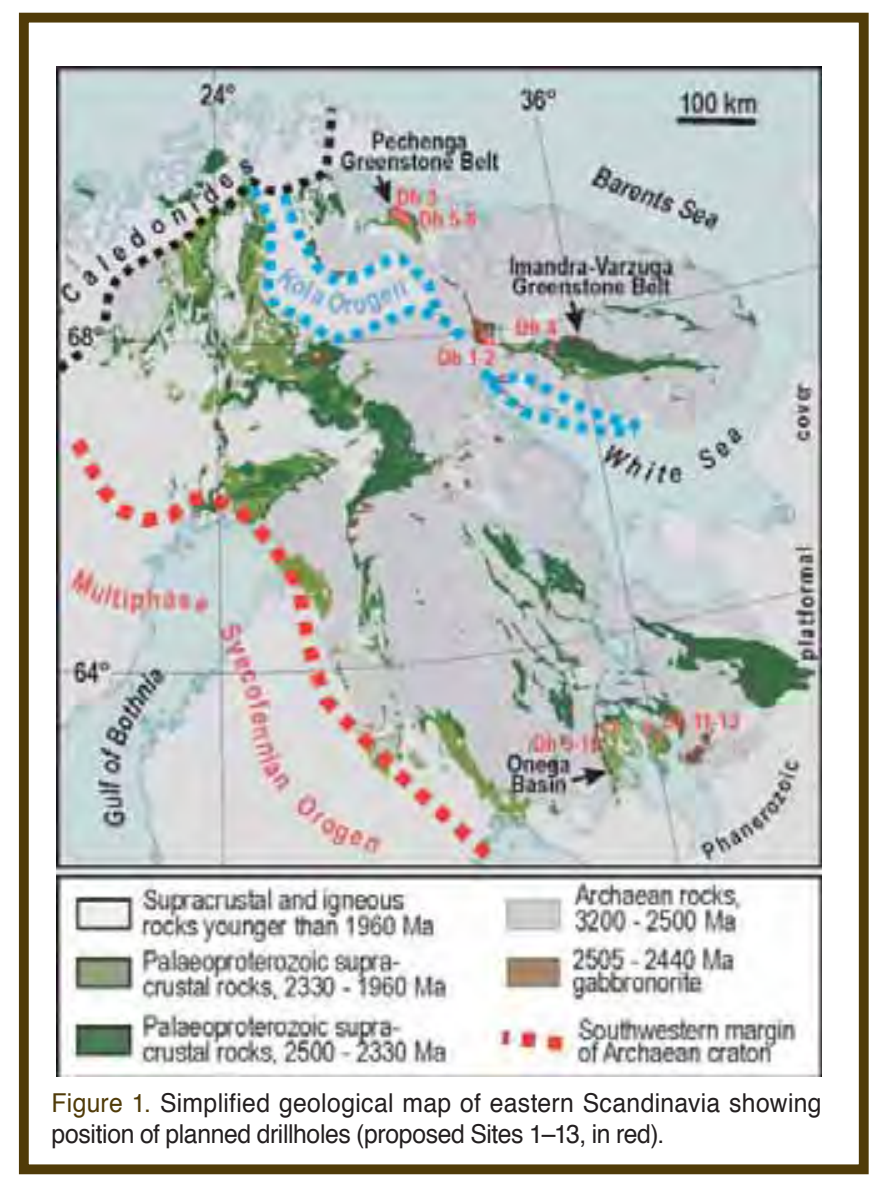

Twenty-eight researchers from nine countries took part in the meeting, including representatives of the ICDP panels and the Federal Agency on Management of Natural Resources of the Russian Federation (ROSNEDRA). The Russian part of the Fennoscandian Shield was selected as a principle area for scientific drilling (Fig. 1) because it is characterized by exceptionally well preserved 2500-1900 Ma-old rocks compared to other regions in Australia, South Africa, and North America where rocks of similar age occur. Of the twelve global events that define worldwide environmental upheavals in the Archaean-Palaeoproterozoic transition (Fig. 2), nine are best developed in Russian Fennoscandia (shown in red), one is equally present in all four continents (shown in green), one is poorly developed (shown in blue) in Fennoscandia, and only one, a 2500-Ma banded iron formation event (shown in white), is missing in the Fennoscandian Shield. The workshop participants agreed that research of this key stage in Earth system evolution would focus on three main objectives: (i) to establish a wellcharacterized, well-dated, well-archived section for the period 2500-1900 Ma; (ii) to document the changes in the biosphere and the geosphere associated with the rise in atmospheric oxygen; and (iii) to develop a self-consistent model to explain the genesis and timing of the establishment of the modern aerobic Earth system. Workshop participants of breakout sessions made up six groups concerned with logistics and on-site geologists, depositional frameworks and basin analysis, stable isotopes, radiogenic isotopes, biosignatures, and palaeomagnetic studies. Each group investigated a series of designated biogeochemical events and processes. The questions of what, why, and where to drill were discussed dynamically throughout the entire workshop. The discussions also addressed how to define the knowns and unknowns of the various events and processes, including mantle evolution, major perturbations in the global carbon, phosphorus, and sulfur cycles, seawater evolution, the Great Oxidation Event, chemical biomarkers, recycling of organic matter, the oldest significant petroleum generation known, the earliest glaciations and their drivers, and palaeolatitudes and palaeomagnetic field reversals.

To obtain the best non-weathered and non-contaminated material recording the major global changes in the terrestrial biosphere and geosphere during this time interval, the workshop participants discussed and selected thirteen drilling sites ( $4000 \mathrm{~m}$ in total) in three geographically distinct regions (Fig. 1). Drilling operations will be performed simul- 


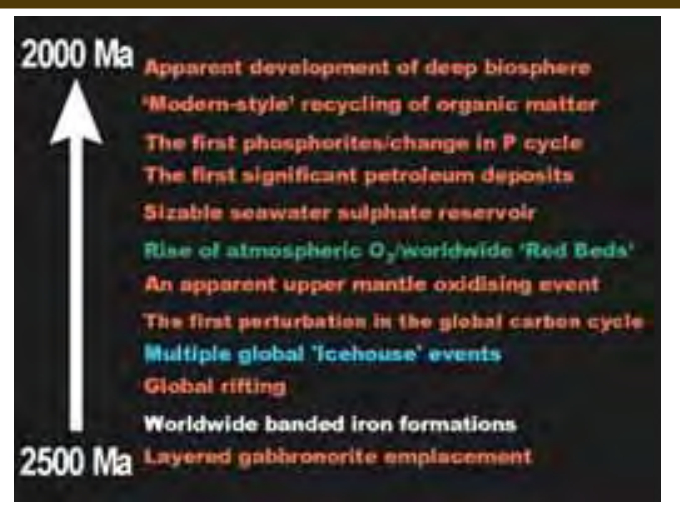

Figure 2. Major Early Palaeoproterozoic events (see explanation in text).

taneously in these areas by hiring local drilling crews. Multiple funding sources including Worldwide Universities Network, national and international funding agencies, and Norwegian and British oil-based companies were discussed. The NGU, Scottish Universities Environmental Research Centre, and Westfälische Wilhelms-Universität will contribute substantial financial support for establishing detailed archived (logged and photographed) and analyzed (thin sections, major and trace elements, $\partial{ }^{13} \mathrm{C}_{\text {carb }}, \partial^{18} \mathrm{O}_{\text {carb }}$, $\left.\partial^{34} \mathrm{~S}_{\text {sulphide }}\right)$ drillcore sections to be housed at the $\mathrm{NGU}$ drillcore storage facility.

Discussions took place about links with NASA astrobiology groups, relevant active International Geoscience
Program (IGCP) and ICDP projects as well as outreach to the general public and education via Web sites and popular newspaper articles. The potential for applied aspects of the research program were recognized; issues included obtaining data useful to the petroleum industry (oil migration distance, chemical and isotopic transformation between in situ, migrated, and spilled petroleum that occurred as early as $2000 \mathrm{Ma}$ ago) and to nanotechnology (occurrence, abundance, and distribution of natural fullerenes in Karelian shungites, a metamorphic bitumen rock).

The creative mood of the workshop resulted in a new project acronym FAR-DEEP, which stands for: Fennoscandian Arctic Russia - Drilling Early Earth Project. The participants were encouraged to move ahead and were further promised support by the ROSNEDRA representative. The project core group is now set to prepare a full drilling project proposal for submittal to the ICDP in 2006.

\section{Authors}

Victor A. Melezhik, Geological Survey of Norway, N-7491 Trondheim, Norway. e-mail: victor.melezhik@ngu.no

Aivo Lepland, Geological Survey of Norway, N-7491 Trondheim, Norway

\section{Related Web Link}

http://far-deep.icdp-online.org 